\title{
Kernos
}

Revue internationale et pluridisciplinaire de religion grecque antique

$34 \mid 2021$

Varia

\section{Noms de dieux. Portraits de divinités antiques}

\section{Vinciane Pirenne-Delforge}

\section{QpenEdition \\ Journals}

\section{Édition électronique}

URL : https://journals.openedition.org/kernos/3978

DOI : 10.4000/kernos.3978

ISSN : 2034-7871

\section{Éditeur}

Centre international d'étude de la religion grecque antique

\section{Édition imprimée}

Date de publication : 31 décembre 2021

Pagination : $302-303$

ISBN : 978-2-87562-305-8

ISSN : 0776-3824

\section{Référence électronique}

Vinciane Pirenne-Delforge, « Noms de dieux. Portraits de divinités antiques », Kernos [En ligne], 34 |

2021, mis en ligne le 31 décembre 2021, consulté le 15 mars 2023. URL : http://

journals.openedition.org/kernos/3978; DOI : https://doi.org/10.4000/kernos.3978

Ce document a été généré automatiquement le 15 mars 2023.

Tous droits réservés 


\title{
Noms de dieux. Portraits de divinités antiques
}

\author{
Vinciane Pirenne-Delforge
}

\section{RÉFÉRENCE}

Corinne BONNET (dir.), Noms de dieux. Portraits de divinités antiques, Toulouse, Anacharsis, 2021. 1 vol. 12,5 × 20 cm, 380 p. (Essais. Série « Histoire »). ISBN : 979-10-279-0408-2.

1 L'université Jean-Jaurès de Toulouse accueille depuis 2017 un projet de grande envergure sur les dénominations divines dans le monde sémitique et le monde grec intitulé Mapping Ancient Polytheisms (MAP). Financé par le European Research Council et dirigé par Corinne Bonnet, il a fait l'objet d'un article de présentation dans le $32^{\mathrm{e}}$ volume de Kernos en 2019 , ce qui permettra d'entrer directement dans le vif de cette recension ${ }^{1}$. En effet, l'ouvrage dont il s'agit de rendre compte est tout droit sorti de cette entreprise, rassemblant, après une introduction et avant une conclusion, également collectives, douze chapitres sous la plume d'auteurs qui, toutes et tous, ont participé - ou participent encore - au projet MAP. Fondé sur une recherche de pointe, ce livre de poche, très agréablement présenté, offre deux étapes d'une promenade destinée aux chercheurs qu'intéressent les noms des dieux, mais aussi à un public cultivé au-delà des cercles académiques. Tous les lecteurs trouveront dans cet ensemble chatoyant un panorama éclairant de la manière dont, sous l'angle de la manière de nommer les dieux, la recherche approche aujourd'hui les polythéismes antiques et le monde de la Bible.

2 À tout seigneur, tout honneur, Homère ouvre la danse sous la plume de Corinne Bonnet qui offre un panorama bienvenu d'une pratique narrative des noms, tant humains que divins, à l'œuvre dans l'épopée. «Ni simples ornements ni purs fossiles d'un passé oral formulaire ", ils contribuent à faire vivre le récit et à créer les conditions de l'interaction entre hommes et dieux. S'ensuit une réflexion sur les noms magiques, au départ d'une incantation grecque d'Égypte adressée à la lune (Thomas Galoppin), une 
autre sur les traces d'un dieu " Maître de la Force » en contexte phénicien, comparé à certains dieux anatoliens (Maria Bianco). Le propos revient en Grèce, avec une investigation originale et fructueuse qui compare Dionysos et Poséidon en leurs différents attributs onomastiques et aboutit à un véritable " exercice de polythéisme " où un dieu permet de mieux penser celui auquel on le compare, et inversement... (Sylvain Lebreton). Mais comment comprendre, en contexte divin pluriel, qu'un dieu soit invoqué comme «Maître de l'Univers/de l'Éternité »? C'est le cas à Palmyre, où il s'avère que ce titre peut s'appliquer potentiellement à chacun des dieux, en fonction du contexte et de l'exaltation circonstancielle qui l'élève au-dessus des autres (Aleksandra Kubiak-Schneider). La même question se pose pour le dieu «total» qu'est Pantheus dans les mondes grec et romain : il n'est pas «tout du divin » mais le «tout divin », ce qui n'est pas la même chose (Ginevra Benedetti). D'autres étapes encore emmènent le lecteur d'abord en Mésopotamie, où les ressorts de l'écriture cunéiforme et les listes qu'elle permet d'élaborer forment autant d'aspects d'une réflexion théologique (Marinella Ceravolo), ensuite en Égypte, où le syntagme Zeus Hélios grand Sarapis est analysé en ses différents contextes (Laurent Bricault), et enfin en pays phénicien, où Melqart "sur le rocher » passe de Tyr à Gadès (Élodie Guillon). Et le dieu de la Bible dans tout cela? En Exode 3, 14, il se présente sous l'expression «Je serai qui je serai ", un puzzle théologique qui a fait couler beaucoup d'encre, et la réflexion s'ouvre ici sur la «grande épopée [du peuple d'Israël] qui se joue, se noue et se dénoue autour des noms de Dieu » (Fabio Porza). Avec les deux dernières étapes de la balade, on revient en Grèce, autour de la chevelure des dieux «blonds» que sont Apollon et Déméter (Adeline Grand-Clément), et avec la paire des filles de Zeus, Artémis et Athéna (Pierre Brulé). Décidément, les dieux grecs sont de bons réactifs les uns pour les autres, ainsi que l'avait montré plus haut le chapitre de Sylvain Lebreton: le dieu doré n'est pas blond comme l'est la déesse, et le paysage épiclétique d'Artémis prend tout son relief face à celui d'Athéna, et inversement... Autant d'exercices de polythéisme particulièrement gratifiants.

En conclusion, «Noms de dieux » est assurément un titre pertinent pour inviter au voyage parmi les dénominations divines. Celles-ci sont analysées sous différents angles qui permettent d'en saisir les très nombreuses potentialités, ainsi que les lignes de force qui traversent tous les contextes étudiés. On pourrait être, a priori, plus réservé sur la formulation "portraits de divinités antiques » qui forme le sous-titre du livre et semble sacrifier un peu rapidement la complexité du sujet à la nécessité d'un label synthétique. En l'occurrence, la notion de "portrait» apparait comme une facilité de langage car le terme entraîne avec lui la notion de représentation fidèle à un modèle qui est ici inexistant. La meilleure preuve en est que les Grecs eux-mêmes, puisant au riche vocabulaire de la statuaire ou de la peinture pour parler des représentations divines, n'en faisaient pas des eikones, des " portraits », mais des agalmata, des « statuesoffrandes", des xoana, des "antiquités ", des anathemata, des "dédicaces", etc. Reconnaissons toutefois que les chercheurs de MAP connaissent parfaitement les limites d'une telle métaphore dont l'introduction du livre tisse la trame avec conviction. 


\section{NOTES}

1. S. LEBRETON, C. BONNET, « Mettre les polythéismes en formules? À propos de la base de données Mapping Ancient Polytheisms », Kernos 32 (2019), p. 267-296.

\section{AUTEURS}

\section{VINCIANE PIRENNE-DELFORGE}

Collège de France, Université de Liège) 